\title{
Desenvolvimento local do Povoado de Melancias frente às transformações do Norte de Minas Gerais
}

\author{
Local development of the Melancias Village due to the transformations of the \\ North of Minas Gerais
}

\section{Développement local de Ville de Melancias face aux transformations du Nord de Minas Gerais}

\author{
Desarrollo local del Pueblo de Melancias frente a las transformaciones del Norte \\ de Minas Gerais \\ Lucas Alves Prates ${ }^{1}$ \\ José de Arimatéia Dias Valadão²
}

Recebido em 29/05/2017; revisado e aprovado em 25/07/2017; aceito em 16/08/2017

DOI: http://dx.doi.org/10.20435/inter.v19i2.1617

\begin{abstract}
Resumo: Este trabalho discutiu o desenvolvimento local frente às proposições desenvolvimentistas modernas, especificamente na região do Norte de Minas Gerais. Teoricamente, foram feitas discussões acerca do conceito de desenvolvimento nos países periféricos e sua relação com o desenvolvimento local. Metodologicamente, foram usadas histórias orais. Os resultados mostram que o desenvolvimento da região impôs novas lógicas ao desenvolvimento local, apresentando, ao mesmo tempo, potencial de desenvolvimento endógeno frente às transformações ocorridas na região.
\end{abstract}

Palavras-chave: desenvolvimento; políticas públicas; desenvolvimento local; Norte de Minas.

Abstract: This paper discusses local development in relation to modern developmental propositions, specifically in the Northern region of Minas Gerais. Theoretically, discussions were held about the concept of development in peripheral countries and their relationship with local development. Methodologically, oral histories were used. The results show that the development of the region has imposed new logics on local development, presenting, at the same time, the potential for endogenous development in the face of the transformations that have occurred in the region.

Keywords: development; public policy; local development; North of Minas Gerais.

Résumé: Ce document a discuté du développement local avant des propositions de développement modernes, en particulier dans la région Nord du Minas Gerais. En théorie, les discussions ont été faites sur le concept de développement dans les pays périphériques et ses relations avec le développement local. Méthodologiquement histoires orales ont été utilisés. Les résultats montrent que le développement de la région a imposé une nouvelle logique au développement local, présentant en même temps, le potentiel de développement endogène face à des changements qui se sont produits dans la région.

Mots-clés: développement; les politiques publiques; developpement local; Nord du Minas Gerais.

Resumen: En este trabajo se discute el desarrollo frente a las proposiciones de desarrollo local, modernas, específicamente en la región del Norte de Minas Gerais. En teoría, se realizaron discusiones sobre el concepto de desarrollo en los países periféricos y su relación con el desarrollo local. Metodológicamente se utilizaron historias orales. Los resultados muestran que el desarrollo de la región impuso nueva lógica de desarrollo local, presentando al mismo tiempo, el potencial de desarrollo endógeno en la cara de los cambios que se produjeron en la región.

Palabras clave: desarrollo; políticas públicas; desarrollo local; Norte de Minas Gerais.

\footnotetext{
${ }^{1}$ Universidade Federal do Rio de Janeiro (UFRJ), Rio de Janeiro, Rio de Janeiro, Brasil.

${ }^{2}$ Universidade Federal de Lavras (UFLA), Lavras, Minas Gerais, Brasil.
} 


\section{INTRODUÇÃO}

A partir da segunda metade do século XX, o desenvolvimento dos países pobres passa a ser visto não mais em comparação somente aos países ricos, mas decorrente de causas locais e específicas (FURTADO, 1974). Dentro desse contexto, teóricos como Nurkse (1953), Myrdal (1972) e Rostow (1964) concebem o desenvolvimento a partir da falta de capital e inversões econômicas nessas regiões. Nesse sentido, o subdesenvolvimento advém da baixa poupança e do baixo capital investido. Assim, ao promover a industrialização em seus territórios, essas nações passariam a percorrer os caminhos já trilhados pelos países desenvolvidos em busca do desenvolvimento.

Contudo, orientados por políticas de industrialização, esses países passaram por transformações na geopolítica global e em suas relações internas, ocasionando dependência frente às nações desenvolvidas e profundas desigualdades em seu interior. Teóricos como Furtado (1974) e Arrighi (1998) questionaram a possibilidade de essas nações se desenvolverem, pois a apropriação da riqueza, tecnologia e recursos naturais ocorreram de maneira desigual na cadeia global de desenvolvimento.

Mesmo diante das críticas oriundas principalmente do próprio contexto latino-americano (PREBISCH, 1968; FURTADO, 2009), da segunda metade da década de 1940 em diante, inicia-se no Brasil um forte processo de industrialização, ocorrido por meio de incentivos estatais e direcionamento de políticas públicas para a infraestrutura produtiva, alterando internamente a dinâmica econômica brasileira. O Norte de Minas Gerais, quando incorporado à área mineira da SUDENE como política de modernização do Nordeste, passa a sofrer profundas transformações sociais e econômicas. Até então, a região que era marcada pelo isolamento em relação aos centros economicamente desenvolvidos, passa a ter inversões de capital baseado na industrialização da cidade de Montes Claros e no cultivo de monoculturas como desenvolvimento de seu território (CUNHA, 2012; MOREIRA, 2010; FRANÇA, 2006).

Esse modelo de desenvolvimento implantado na região levou a profundas alterações em seu interior, onde as comunidades locais passaram a integrar as dinâmicas de desenvolvimento regional. Isso é o caso do povoado de Melancias, localizado no município de Japonvar, MG, que teve seu território alterado diante dessas transformações. Teóricos como Sen (2000), Ávila (2006), Schumacher (1977), Furtado (2009), Oliveira (2001), dentre outros, destacam, contudo, que o desenvolvimento não deve pautar-se somente na dinâmica industrial e crescimento econômico, mas deve levar em conta a cultura local (FURTADO, 2009), as tecnologias (SCHUMACHER, 1977) e as liberdades que as pessoas possam desfrutar no âmbito de seu território (SEN, 2000). Ou seja, o desenvolvimento deve ser local e pautado em processos autônomos de relações entre as pessoas e o meio natural e cultural em que vivem, mediados por tecnologias locais adequadas à manutenção e expansão dessas relações.

Ao basear somente no contexto econômico e industrial, as políticas que visam transformações das localidades pobres, como é o caso do Povoado de Melancias, acabam por acentuar ainda mais as diferenças culturais, econômicas, ambientais e sociais dessas localidades, gerando um processo de exclusão e subdesenvolvimento. Por outro lado, as formas como as próprias comunidades têm atuado na busca de soluções para essas exclusões sociais e econômicas, podem suscitar políticas que tenham uma maior simetria entre as ações endógenas dessas localidades e as políticas externas que visam o desenvolvimento local. É nesse sentido que este trabalho questiona: como ocorreu o desenvolvimento local de comunidades pobres, como o Povoado de 
Melancias, frente às proposições desenvolvimentistas modernas? Para responder essa questão, o trabalho está estruturado, além dessa introdução, de referencial teórico, procedimentos metodológicos, apresentação e discussão dos resultados e conclusões sobre o tema.

\section{REFERENCIAL TEÓRICO}

\subsection{O subdesenvolvimento e o desenvolvimento local}

As primeiras análises acerca do subdesenvolvimento tentaram explicar a questão da pobreza dos países periféricos a partir da ótica dos países centrais. Para essas análises, a pobreza era originária da falta de mercado e pela ausência do estado na promoção do crescimento econômico. Nesse sentido, o estado e o mercado seriam agentes que induzem e promovem, respectivamente, o desenvolvimento. O objetivo central dos países periféricos deve ser, nessa perspectiva, de alcançar patamares econômicos comparáveis aos países centrais (ROSTOW, 1964).

Essa visão do subdesenvolvimento trata da modernização explicada pelos países ricos, ou seja, a incapacidade dos países pobres em acompanhar a lógica de demanda do comércio exterior se dá pela escassa produtividade e pequena capacidade tecnológica. Além da influência da alta taxa de população rural nesses países que provoca o desemprego, e com o baixo aproveitamento da mão de obra disponível, isso gera também desemprego disfarçado, ou seja, um consumo efetivo maior do que a produtividade real dos trabalhadores.

Enquanto para os teóricos dos países desenvolvidos, como foi o caso acentuadamente de Nurkse (1953), o desenvolvimento e o subdesenvolvimento foram vistos como etapas de um mesmo processo, ou seja, o desenvolvimento é um processo integrado, onde os processos industriais dinamizam o crescimento econômico, favorece o reordenamento das estruturas sociais e quebra a estagnação econômica, ou o círculo vicioso, como foi comumente nomeado. Para os teóricos latino-americanos, contudo, como é o caso de Furtado (2009), o subdesenvolvimento não se vincula ao desenvolvimento, pois trata de um processo autônomo, não estando os países pobres em "estágios de desenvolvimento". A pobreza, para Furtado, não é um estágio na dinâmica evolutiva dos países, mas uma condição, uma característica intrínseca ao desenvolvimento. Na sua análise, "o crescimento de uma economia desenvolvida é, portanto, principalmente, um problema de acumulação de novos conhecimentos científicos e de progressos na aplicação tecnológica desses conhecimentos. O crescimento das economias subdesenvolvidas é, sobretudo, um processo de assimilação da técnica prevalecente na época" (FURTADO, 2009, p. 85). Desse modo, o subdesenvolvimento de algumas regiões globais é uma condição necessária para sustentação do desenvolvimento de outras.

A saída do subdesenvolvimento por meio de adoção de processos similares aos adotados pelos países ricos, foi vista, desse modo, como mito (FURTADO, 1974), ilusão (ARRIGHI, 1998) ou economicamente equivocada (SCHUMACHER, 1977; SEN, 2000). Para Furtado (1974), não é possível os países periféricos atingirem os níveis econômicos e industriais dos países ricos devido a dois aspectos centrais. Primeiro, a relação de transformação do mundo físico em desenvolvimento econômico e, segundo, a constituição histórica do sistema de acumulação capitalista, levando em conta a relação internacional do trabalho. No primeiro, caso o desenvolvimento fosse alcançado por todos os países, a degradação do meio ambiente e as explorações humanas e naturais levariam regiões inteiras ao colapso. No segundo, assim como destacou Arrighi (1998), as relações de troca e a expansão do mercado internacional proporcionaram relações de subdesenvolvimento e, consequentemente, dependência em toda a periferia. 
Para Furtado (1984), a questão cultural é um elemento relevante para repensar as questões de dependência e desenvolvimento na América Latina. O processo de mimetismo, influenciado pela identidade cultural da elite brasileira, aliado ao processo de consumo de massa, reafirma essa dependência na divisão internacional do trabalho. Porém, Furtado (1984) tem um certo otimismo quanto ao papel da cultura nas transformações sociais, políticas e econômicas, vendo-a como elemento fundamental para geração de alternativas ao processo de modernização dependente instalado no País. Isso, pois, o processo de inovação política requer "[...] um reencontro das lideranças políticas com os valores permanentes de nossa cultura [...]. Sem isso, o desenvolvimento futuro não se alimentará de autêntica criatividade e pouco contribuirá para a satisfação dos anseios legítimos da nação" (FURTADO, 2002, p. 3).

Nesse sentido, a valorização cultural permite surgir uma identidade endógena, capaz de adequar outras variáveis como é o caso dos processos econômicos, às necessidades locais (ROCHA, 2012). Como destacou Guerreiro Ramos (2009), com isso o desenvolvimento passa a ser questionado, deixa de seguir o caminho da necessidade e passa a se constituir como uma possibilidade (RAMOS, 2009). Isso significa que o local passa a incorporar novas possibilidades a partir das ressignificações de seus próprios contextos internos (SCHUMACHER, 1977). Ávila (2006, p. 59) argumenta que o desenvolvimento local "pressupõe alterações nas maneiras de como as comunidades-localidades envolvidas se relacionam com os paradigmas do desenvolvimento em curso". Esse pressuposto, assim como assinalou Oliveira (2001), requer novas considerações acerca do local nas dinâmicas de desenvolvimento.

Para Schumacher (1977), o desenvolvimento na perspectiva local, ou o que ele chama de regional, contesta o "pressuposto implícito de que o setor moderno pode ser ampliado para absorver praticamente toda a população" (SCHUMACHER, 1977, p. 149). Para ele, extinguir a agricultura natural em prol de um processo industrial hegemônico é abrir mão de bases essenciais da vida humana, que não são materiais, mas imateriais por natureza, como são os processos humanos organizativos e sua capacidade de aprendizagem.

O principal pressuposto de Schumacher é que o "desenvolvimento não pode ser encomendado, comprado ou planejado em termos globais" (SCHUMACHER, 1977, p. 150), mas é preciso um "enfoque regional de desenvolvimento" que privilegie uma tecnologia intermediária, acessível, pertencente e inter-relacionada com as pessoas. Seu argumento é que, ao priorizar uma política desenvolvimentista que pressupõe nações, como um todo, serão privilegiados, sobretudo, os grandes conglomerados urbanos que concentram os modernos sistemas de produção responsáveis pelos processos epidêmicos de envenenamento. Para ele, a saída é a criação de indústrias onde as pessoas vivem; suficientemente baratas para que sejam acessíveis a todos; com processos produtivos simples; e com métodos de produção dependentes dos materiais locais e para o consumo local. Tecnologia intermediária preserva o trabalho, permite a reconstituição da natureza, privilegia o local em vez do global e torna variável aquilo que a perspectiva hegemônica de desenvolvimento estabeleceu como variáveis independentes, como é o caso do capital e da tecnologia empregados.

Isso significa dizer que o desenvolvimento é um alargamento das capacidades individuais das pessoas de um determinado território. Para Sen (2000, p. 16), o desenvolvimento é "um processo de expansão das liberdades reais que as pessoas desfrutam", ou seja, "a condição de agente livre e sustentável emerge como motor fundamental do desenvolvimento" (SEN, 2000, p. 18). Do mesmo modo, desenvolvimento pode ser compreendido como "eliminação das privações de liberdade que limitam as escolhas e as oportunidades das pessoas de exercer ponderadamente 
sua condição de agente" (SEN, 2000, p. 10). Enquanto Schumacher foca, sobretudo, nas tecnologias locais, Sen (2000) considera principalmente as liberdades instrumentais e substantivas, ou seja, as "liberdades não são apenas os fins primordiais do desenvolvimento, mas também os meios principais" (SEN, 2000, p. 25). Enquanto as liberdades instrumentais são meios para alcançar desenvolvimento, como educação, saúde, proteção, direito à economia e participação política, as liberdades substantivas, que podem significar essas mesmas liberdades, é o próprio desenvolvimento em si.

O argumento de Sen sobre as liberdades instrumentais é que elas por si só não geram autonomia das pessoas. Ter renda alta não significa diretamente que as pessoas terão condições de desenvolver suas capacidades; os níveis de pobreza nem sempre estão proporcionalmente relacionados aos níveis de desigualdades; a baixa renda não está diretamente relacionada à mortalidade; os níveis de liberdade da mesma forma não correlacionam diretamente com a qualidade de vida e; nem sempre o acesso a mercados significa prática econômica autônoma. Esses desequilíbrios, para Sen (2000), são passíveis de serem sanados por meio de liberdades instrumentais, mas que por si só, não garantem liberdades substantivas. Essas últimas são alcançadas quando as pessoas conseguem praticar plenamente sua condição de agente. Agente no sentido "de alguém que age e ocasiona mudança e cujas realizações podem ser julgadas de acordo com seus próprios valores e objetivos, independentemente de as avaliarmos ou não também segundo algum critério externo" (SEN, 2000, p. 34).

O Desenvolvimento, numa perspectiva local, desse modo, considera suas próprias chances efetivas e emancipadoras de transformações sociais, econômicas, políticas, tecnológicas e ambientais, rompendo com as amarras internas e externas que o prende aos estados tradicionais de pobrezas e mazelas sociais. Nesse sentido, desenvolvimento local significa romper com a "cultura da pobreza" que considera o desenvolvimento como sinônimo de riqueza (ÁVILA, 2006). Isso permite que as comunidades locais sejam protagonistas de seu próprio bem-estar e de alternativas sociais e técnicas adequadas às suas culturas e valores, baseando-se em laços de solidariedade e cooperação (SEN, 2000). Assim, desenvolvimento local (DL) é o

[...] O efetivo desabrochamento das capacidades, competências e habilidades de uma comunidade definida [...], no sentido de ela mesma se tornar paulatinamente apta a agenciar [...] o aproveitamento dos potenciais próprios recursos [...] visando potenciais busca de soluções para os problemas, necessidades e aspirações, de toda ordem e natureza, que mais direta e cotidianamente lhe dizem respeito. (ÁVILA, 2000, p. 68).

O DL, nessa perspectiva, exige uma distinção entre Desenvolvimento Local Exógeno (DLEx) e Desenvolvimento Local Endógeno (DLEn). Esses dois conceitos não podem ser considerados isoladamente, ambos são parte de um processo constitutivo, retroalimentado e incorporado um pelo outro. O DLEx concebe o DL como "[...] quaisquer agentes externos que se dirigem à comunidade localizada para promover melhorias de suas condições e qualidade de vida, com a participação ativa da mesma" (ÁVILA, 2000, p. 68). Enquanto o DLEn concebe o DL por meio da própria comunidade. Assim, ela "[...] desabrocha suas capacidades, competências e habilidades de agenciamento e gestão das próprias condições e qualidade de vida metabolizando comunitariamente as participações efetivamente contributivas de quaisquer agentes externos" (ÁVILA, 2000, p. 68).

O desenvolvimento local deve ter como objetivo principal o aprimoramento dos laços comunitários e solidários existentes localmente, sendo a solidariedade o pilar central da autoprodução da comunidade. Ávila (2006, p. 103) descreve os laços de solidariedade "[...] como 
coesão solidária, ou volitiva, emotivamente consciente e assumida para cada um e todos os componentes do grupo nesse estado de auto vinculação".

\subsection{O Sertão do Norte de Minas: formação e alterações}

O povoamento da região norte mineira, em um primeiro momento, ocorreu com o avanço dos currais baianos e as expedições das bandeiras paulistas. A partir da dinâmica do ciclo do ouro, a região se consolidou em uma formação peculiar no estado de Minas Gerais, 'o Sertão das Gerais e as Minas Gerais'. No início desse período, a Região dos Currais São Franciscanos supria com gêneros alimentícios outras regiões mineiras que se dedicavam à extração de ouro (MOREIRA, 2010).

O sertão foi habitado por populações que cresciam em torno da grande fazenda: vaqueiros, meeiros, trabalhadores assalariados, agregados, arrendatários, posseiros e outros grupos que se estabeleciam por laços de parentescos e produtivos entre a grande fazenda e a pequena propriedade; e pelas populações que habitavam os sertões organizadas em grupos autônomos, aproveitando do ambiente natural para seu auto sustento. Esses últimos usavam as chapadas e margens de rios para o uso coletivo de plantio e criatório de gado, estabelecendo poucas relações com as grandes fazendas, caracterizando o que Costa (1997, apud CUNHA 2012) chama de "todo econômico", que é a relação de autoprodução e autoconsumo para reprodução da vida local.

Com o fim do ciclo do ouro, a região entrou em um longo período de decadência, envolvendo-se em um relativo isolamento que perdurou até início da década de 1960 . O afastamento do Norte de Minas às outras regiões do País possibilitou uma formação cultural particular à região. O bioma e a apropriação de territórios específicos moldaram uma matriz cultural sertaneja que se manifestou em cinco diferentes povos, conhecidos como Geraizeiros, Catingueiros, Negros do Jayba, Vazanteiros e Xakirabas, todos em constantes relações e trocas simbólicas (COSTA, 2005).

Em 1963, o Norte de Minas foi integrado à área de atuação da SUDENE. Três aspectos se destacam para que isso tenha ocorrido. Primeiro, pela região pertencer ao polígono da seca. Segundo, por conter baixos indicadores sociais e econômicos. E, sobretudo, por ter uma formação cultural semelhante à Região Nordestina. Por ser uma região sem relevância política e econômica, se comparada ao restante do Estado de Minas Gerais, a incorporação à SUDENE foi um importante marco para a história da região, que, a partir desse momento, passou por uma modernização produtiva, tanto na cidade e como nas áreas rurais (MOREIRA, 2010).

Entretanto essa incorporação beneficiou, quase que exclusivamente, as elites locais, que por meio de incentivos fiscais e linhas de créditos, criaram grandes empresas rurais voltadas para o reflorestamento e criação de gado de corte. Esses meios de produção concentradores de terra e com pouca absorção de mão de obra local resultou na expulsão de trabalhadores rurais, além da institucionalização de fenômenos migratórios temporários para o interior paulista e para outras regiões mineiras (FONSECA, 2009). Montes Claros, beneficiando-se dos mesmos incentivos e da pré-disposição de investimento das suas elites locais, despontou como polo industrial da região e como principal centro de referência entre o eixo centro-sul do País (MOREIRA, 2010).

\section{PROCEDIMENTOS METOdOLÓGICOS}

Em termos de delineamento de pesquisa, o trabalho assumiu o caráter exploratório, devido à ausência de material relacionado ao objeto, sendo a estratégia de investigação adotada a pesquisa narrativa. Entende-se como pesquisa narrativa "o método pelo qual o pesquisador 
estuda a vida das pessoas e pede para uma ou mais contar histórias sobre sua vida" (CRESWELL, 2007, p. 32). Esse método permite compreender por meio de histórias pessoais, contadas pelos moradores do local, a história do próprio Povoado.

Os dados coletados foram organizados e segmentados a partir dos pontos em comum das diferentes histórias de vida pesquisadas e interpretadas a fim de responder o objetivo geral de pesquisa, ou seja, analisar a constituição do desenvolvimento local da comunidade rural de Melancias, além dos objetivos específicos de (1) compreender a relação de transformação do Norte de Minas com o povoado, (2) analisar de forma cronológica, a história e a formação do lugar a que pertence o povoado por meio das políticas públicas e (3) compreender a relação da comunidade com o desenvolvimento local.

As entrevistas foram coletadas entre os dias 18 de junho de 2015 e 26 de junho de 2015, período em que ocorrem as fogueiras de São João e São Pedro no povoado. Por ser um período de festas tradicionais, a aglomeração de moradores e ex-moradores no povoado é intensa, o que facilita a coleta dos dados nesse período em relação às outras épocas do ano, quando ocorre um esvaziamento do povoado ocasionado pelas migrações temporárias. As entrevistas não tiveram delimitação de tempo prévio, a fim de deixar os entrevistados mais à vontade em narrar suas histórias. No decorrer das entrevistas, foram feitas perguntas e anotações de campo a fim de aprofundar os conceitos abordados nesse trabalho.

Os critérios estabelecidos para a escolha dos entrevistados foram: (I) ter vínculos duradouros com a comunidade; (II) ter permanecido a infância na comunidade; (III) ter participado ativamente em algum momento na construção do local e; (IV) ser morador ou ex-morador da comunidade. Foram selecionados 6 entrevistados indicados por moradores da comunidade. $O$ Entrevistado A, um dos primeiros moradores do lugar, testemunhou a pré-formação, a formação e as alterações locais. O Entrevistado B foi liderança política da comunidade nas décadas de 1980 a 1990 e participante ativo da construção do Povoado. O Entrevistado C, ex-morador, permaneceu até aos 25 anos como morador da comunidade e acompanhou a formação da comunidade desde seu início. A Entrevistada $D$, ex-moradora do lugar, viveu na região antes da formação do povoado. O Entrevistado E, morador, ex-migrante temporário, nasceu no povoado depois da sua constituição. E, por último, o Entrevistado F, primeiro morador do local e um dos moradores mais velhos da comunidade.

As entrevistas foram gravadas em áudio e transcritas de maneira literal para a análise dos dados. Os dados coletados foram organizados e analisados da seguinte forma: 1) Conjunto de falas relacionadas ao período anterior à década de 1970. As informações obtidas para análise desse período foram dos entrevistados $A, B, C, D$ e F, por serem moradores nascidos na década de 1950 ( $A, B$ e F) e 1960 (C e D). A organização das falas desse conjunto de entrevistas originou a seção "A vida lá embaixo"; 2) Conjunto de falas relacionadas às políticas públicas e às transformações do povoado no período de 1970 até 2015. Foi construída uma linha do tempo que mostra a chegada das políticas públicas e as alterações ocorridas no povoado nesse período. As falas dos Entrevistados A, B, C e F contribuíram para a seção "A subida: Consolidação do Povoado das Melancias" e, por último; 3) um conjunto de falas relacionadas às Migrações Temporárias, o qual compõe o conteúdo da mesma seção. As entrevistas que contribuíram para tratar as Migrações Temporárias foram dos entrevistados A, B, C e E e foram complementadas com dados secundários acerca do tema. 


\section{APRESENTAÇÃO E DISCUSSÃO DOS RESULTADOS}

\subsection{A Comunidade Rural das Melancias: a vida lá embaixo}

A Comunidade Rural das Melancias guarda traços muito particulares que se assemelham em grande parte aos Catingueiros, povos tradicionais da região que habitavam a caatinga e se dedicavam ao comércio de algodão em tempos pretéritos. Nas palavras da entrevistada $D$, ela diz que o "[...] pai mesmo enchia aquelas carroças de algodão e ia vender lá na Lontra". O Entrevistado A, morador da comunidade, relata a dificuldade para o autossustento do comércio de algodão, onde "[...] a gente não tinha dinheiro né, se a gente perde a lavoura acabou o recurso, a gente colhia o milho, o feijão e o algodão vendia".

Além da questão cultural, outro fator importante para compreensão do povoado foi a interiorização das políticas públicas, principalmente da energia elétrica. $\mathrm{O}$ acesso à energia significou o acesso a bens de consumo duráveis e uma melhoria nas condições cotidianas dos moradores. Isso evidenciou um sentimento de pertencimento à região e de valorização da vida local. Nesse sentido, a vida lá embaixo refere-se ao modo de vida antes da aglomeração do povoado e de acesso às políticas como a energia. Sobre qualquer fato passado, dizem que "quando a gente morava lá embaixo" ou "quando a gente morava na roça". A vida lá embaixo significa um estágio anterior à existência do povoado e falta de infraestruturas básicas. Não existia energia, água encanada, médico, telefone, casas com cimento e bloco, ou seja, a vida era completamente desprovida de bens essenciais e de políticas públicas de bem-estar já existentes em outras regiões. A chegada dessas infraestruturas de maneira localizada, principalmente a partir da segunda metade da década de 1970, provocou um êxodo dessa população para a localidade em que se formou o povoado.

As casas, quando ainda não existia o povoado, eram feitas de enchimento, nome popular das casas feitas de pau-a-pique. "[...] Nessa época, as casas eram mais de enchimento, fincava o pau e enchia de barro, o alicerce da casa era feito de caieira, a gente queimava a pedra e moIhava, até derretia e soltava o cal, não existia cimento" (ENTREVISTADO A). Nota-se que, além de formas de construção, o camponês norte-mineiro fazia uso de formas de habitação muito peculiares à época, "[...] as camas eram feitas de vara, colocava uma ao lado da outra e fazia uma cama, com um colchão de pano de saco e palha de banana" (ENTREVISTADA D). As noites eram iluminadas com lamparinas, ou candeias, nome popular desses instrumentos na região. Para armazenar alimentos, usava-se um caixote de madeira feito de tábua, "[...] aí fazia uma camada de areia e colocava feijão, outra camada de areia e mais feijão, aí quando ia cozinhar no fogão a lenha [...]" (ENTREVISTADA D).

A água usada no ambiente doméstico era buscada em poços e nascentes da região. Geralmente os responsáveis por essa tarefa doméstica eram mulheres e crianças, que traziam a água apanhada em potes de barro, transportada na própria cabeça ou por meio de animais e usada para lavar louças, tomar banho e beber. Essa mesma dificuldade de acesso à água se repetia para lavar roupa, na qual as lavadeiras necessitavam ir à margem de algum córrego para realizar tal atividade. A busca pela água representa sinais da pobreza rural existentes na região do polígono da seca, englobando parte do Norte de Minas e regiões do Nordeste brasileiro.

Entre os produtos colhidos resultantes das atividades produtivas, estava o "[...] milho, feijão, algodão, fava, mandioca, amendoim" (ENTREVISTADO C). Praticamente toda a produção era destinada ao consumo próprio, e somente o algodão era vendido para aquisição de outros produtos necessários. "[...] plantava algodão e vendia para comprar o que não plantava, tipo 
café e arroz", como relata o Entrevistado D. Isso ocorre devido ao algodão ser o principal meio de renda da população catingueira (MOREIRA, 2010). O declínio do algodão, ocasionado principalmente pela existência cada vez maior de pragas e incentivo ao algodão importado no cenário nacional, fez com que essa população buscasse outras formas de garantir renda.

Todavia, quando não chovia o esperado no período chuvoso, a seca castigava os moradores, trazendo consigo a fome e outras formas de pobreza, que se revelam na ausência de comida. Em períodos assim, a palma era o principal alimento das famílias. "[...] o povo vivia com as coisas que só colhia pra cá, arroz mesmo o povo só fazia que comia", relata o Entrevistado B. Nas comemorações festivas e consequentemente no pagamento das dívidas ao comércio local, essas dificuldades também se acentuavam. Nota-se também que, a partir dos programas de combate à fome e distribuição de renda do Governo Federal, como o Bolsa Família, a população passou a ter um outro olhar para a ausência de comida, como descreve novamente o entrevistado $\mathrm{B}$, "[...] o povo veio comer carne mesmo de dois mil pra cá, deve ser por isso que a gente fala que antigamente as carnes eram gostosa demais".

A seca e a fome, principalmente aquela ocorrida no ano de 1976, é outro fator chave para compreender o desenvolvimento do povoado até os dias atuais. A precarização do trabalho, a fome e a dificuldade de colher, principalmente o algodão, coincide com o mesmo período em que as políticas de desenvolvimento para a região implementadas pela SUDENE começaram a surtir efeito. Assim, as florestas energéticas, fruto do incentivo ao agronegócio, e o desenvolvimento industrial de Montes Claros passam a ser uma alternativa à população local. O quadro 1 traz as transformações antes e depois da incorporação do Povoado à SUDENE.

\begin{tabular}{|c|c|}
\hline \multicolumn{2}{|r|}{ Região Norte Mineira } \\
\hline $\begin{array}{l}\text { Antes da } \\
\text { Incorporação à } \\
\text { SUDENE }\end{array}$ & $\begin{array}{l}\text { Tradições resultantes de heranças passadas que geravam laços de solidariedade e } \\
\text { se tornavam bases de sustentação dessas populações, como trabalho em mutirões, } \\
\text { as relações de vizinhanças e também a figura da parteira, das benzedeiras, dos } \\
\text { raizeiros e outros atores importantes para as relações de vizinhanças locais (CUNHA, } \\
\text { 2012). Além da relação de Autoprodução e Autoconsumo, fruto do isolamento da } \\
\text { região às grandes capitais. }\end{array}$ \\
\hline $\begin{array}{l}\text { Depois da } \\
\text { Incorporação à } \\
\text { SUDENE }\end{array}$ & $\begin{array}{l}\text { Incorporação da Região à SUDENE em 1963. Começaram os projetos de } \\
\text { modernização da região por meio de infraestrutura, incentivos fiscais e de crédito. } \\
\text { Montes Claros se despontou como polo industrial e de projetos Agroindustriais } \\
\text { para cultivos de monoculturas (eucalipto e carvão) na tentativa de superação do } \\
\text { isolamento econômico e político da região. A partir desse momento, transformações } \\
\text { nos territórios dos povos tradicionais aconteceram incorporando-os às dinâmicas } \\
\text { produtivas de modernização. }\end{array}$ \\
\hline \multicolumn{2}{|r|}{ Povoado das Melancias } \\
\hline $\begin{array}{l}\text { Antes da } \\
\text { Incorporação à } \\
\text { SUDENE }\end{array}$ & $\begin{array}{l}\text { "A gente só alimentava com o que plantava na roça, o que colhia né, ele fazia } \\
\text { rapadura também, e os cafés a gente adoçava com rapadura" (ENTREVISTADO D). } \\
\text { "Meu pai, ele plantava algodão e colhia, e vendia pra compraralguma coisa que não } \\
\text { plantava, tipo café, o arroz" (ENTREVISTADO D). "As crianças, quando ficava com } \\
\text { febre ou vomitando, eles levavam na benzedeira, aí a pessoa benzia, aí eles davam } \\
\text { chá de hortelã, de erva cidreira, mas não tinha médico nenhum pra gente não" } \\
\text { (ENTREVISTADO C). "Era longe para ir procurar um médico, hoje é Brasília de minas } \\
\text { o hospital mais próximo, naquela época, era parteira mesmo" (ENTREVISTADO A). } \\
\text { "Falava fornecimento, saia no mês de setembro ia lá no comerciante e fazia um } \\
\text { fornecimento, para atravessar seis, sete meses, aí na seca colhia o algodão (julho, } \\
\text { agosto) e ia pagar aquela dívida com juros" (ENTREVISTADO A). }\end{array}$ \\
\hline
\end{tabular}




\begin{tabular}{|c|c|}
\hline $\begin{array}{l}\text { Depois da } \\
\text { Incorporação à } \\
\text { SUDENE }\end{array}$ & $\begin{array}{l}\text { "A juventude não quer mais viver igual nóis viveu [...] de setenta pra cá veio só } \\
\text { melhorando" (ENTREVISTADO B). "A origem do povo procurar o povoado foi por } \\
\text { causa da energia, colocou nas ruas, aí o povo já foi buscando sair da zona rural } \\
\text { e vir pra cá, por modo de energia e água também" (ENTREVISTADO A). "Cisterna } \\
\text { (1974), Escola (1985), Associação (1985), Posto de Saúde (1985), Encanamento } \\
\text { (1988), Energia Elétrica (1986), Orelhão (1994)". "O povo foi começar a sair pras } \\
\text { fazenda em setenta e seis, quando começou a descobrir o carvão" (ENTREVISTADO } \\
\text { A). "Setenta e seis foi uma crise disgramada, aquele tempo a salvaguarda do } \\
\text { povo foi o carvoeiro" (Entrevistado B). "Na verdade meu primeiro serviço foi em } \\
\text { São Paulo, não gostei, nunca gostei da cidade, vim embora e como não tem outro } \\
\text { serviço, eu moro aqui na zona rural, fui obrigado a sair. O primeiro serviço que eu } \\
\text { achei foi de motosserra, já tinha } 21 \text { anos de idade, como não tinha outro serviço e } \\
\text { não tinha estudo, fui obrigado a começar nisso, daí em diante fiquei nesse serviço } \\
\text { durante cinco anos, e a gente trabalhava na SIDERPA, que é uma siderúrgica que } \\
\text { fica no município de João Pinheiro, só que essa empresa a gente não trabalhava } \\
\text { pra ela, porque o serviço era terceirizado, a SIDERPA prestava serviço pra Gerdau" } \\
\text { (ENTREVISTADO E). }\end{array}$ \\
\hline
\end{tabular}

Quadro 1 - Transformações do Norte de Minas e o Povoado das Melancias

Fonte: Elaborado pelos autores.

\subsection{A seca de 1975/76 e as implicações pré-comunitárias}

Na seca de 1975/76, a precariedade do trabalho se agravou. Para as mulheres, responsáveis pela manutenção do serviço doméstico, esse período foi de muita dificuldade de obtenção de água, principalmente pela sua ausência nos olhos d'água que secaram e pelo esforço físico feito diante das longas distâncias, afetando assim toda a vida doméstica. "[...] Na seca mesmo, na época dificil, rompia até três quilometros pra pegar uma vasilha de água na cabeça" (ENTREVISTADO A). Além disso, relata o entrevistado B, "[...] quando apertava mesmo, o povo levantava era meia noite para pegar água, senão, não achava".

Para os homens responsáveis pelo trabalho na roça, a situação piorava nos períodos de colheita, que coincidia com os períodos de pagar mantimento adquirido a prazo. Assim, as dificuldades de sobrevivência local se agravavam, pois a falta de água impedia a produtividade da lavoura, que, além da consequência da fome, levava ao endividamento das famílias. O Entrevistado A relata que "[...] a gente plantava naquele tempo as lavouras até que dava, mas tinha as crises de sol também, que não chovia, aí tinha ano que perdia as lavouras". Do mesmo modo, "[...] Meu pai mesmo quando perdeu as lavouras teve que vender uma pareia de boi porque não deu quase algodão" (ENTREVISTADO B), evidenciando a dificuldade vivida na época.

Coincidentemente, a seca ocorrida na época de 1975/1976, tida como uma das secas mais difíceis da história da região, ocorreu no mesmo período em que as políticas de industrialização e modernização agrícola feita pela SUDENE passaram a surtir efeitos. A partir dessa época, os agricultores descobriram os carvoeiros como alternativa à crise enfrentada. $\mathrm{O}$ entrevistado $\mathrm{B}$ relata o início das migrações, "[...] foi em setenta e seis mesmo que o pessoal começou a sair". Ilustrando a crise enfrentada, o entrevistado A complementa, "[...] aquele tempo a salvaguarda do povo foi o carvoeiro, a sobrevivência deles, o pessoal saia para os carvoeiros para trabalhar e ganhava uns trocado para comprar as coisas".

Por estarem incluídos em um território que permitia a agricultura de subsistência em determinados períodos do ano, além formação cultural catingueira que valorizava as raízes históricas, 
a seca e a decadência do comércio de algodão institucionalizaram as migrações temporárias, já que as famílias permaneceram na região, indo somente os homens trabalharem em Montes Claros e outras regiões que exploraram as carvoarias. Essa institucionalização se deu, pois os filhos daqueles que começaram o processo migratório também seguiram o mesmo caminho.

A primeira vez que eu saí foi para São Paulo, não gostei, nunca gostei da cidade, vim embora e como aqui não tem outro serviço, eu moro aqui na zona rural, fui obrigado a sair, o primeiro serviço que eu achei foi de motosserra, já tava com 21 anos de idade, como não tinha outro serviço fui obrigado a começar nisso, a gente trabalhava para a SIDERPA, que é uma siderúrgica que fica no município de João Pinheiro. (ENTREVISTADO E).

O destino dos migrantes temporários empregados pela SIDERPA, segundo o entrevistado $E$, era para "Três Marias" (noroeste de Minas Gerais, divisa com o Norte de Minas), "Lagoa Santa" (região metropolitana de Belo Horizonte), "Pirapora" (Norte de Minas), "Itacarambi" (Norte de Minas), "Ibia" (Triângulo Mineiro) e "Uberlândia" (Triângulo Mineiro). Esses destinos revelam a integração dos moradores do povoado à região norte mineira e outras regiões do estado de Minas Gerais. Além disso, o trabalho para a construção civil e outros setores se tornou comum nas cidades como São Paulo, Belo Horizonte e Montes Claros. A dinâmica dos moradores do povoado, conjuntamente às dinâmicas desenvolvimentistas do Norte de Minas, representou sua integração direta à periferia desses centros industriais. A institucionalização das Migrações Temporárias no povoado ajuda na compreensão da dinâmica local. Nesse sentido, Furtado (1974) e Arrighi (1998), ao estudarem o desenvolvimento a partir da periferia, argumentam que os países periféricos mantêm essa condição devido à exploração das suas reservas de recursos naturais e o aproveitamento da mão de obra barata, alimentando o regime de trocas desiguais e riqueza oligárquica.

Concomitantemente ao início das migrações, o território da comunidade de Melancias começou a se alterar. Algumas políticas públicas marcantes para sua constituição, como o loteamento, encanamentos de água, energia e novas formas de associação, são fatores que em conjunto fazem a "feição" do povoado.

Assim, as mudanças ocorridas não dizem respeito somente às migrações temporárias, causadas pela seca, mas outras alterações no território ocorreram provenientes da chegada das políticas públicas e mobilização da comunidade em prol do seu próprio desenvolvimento. A primeira forma de organização começou com a construção da escola comunitária. Como não existia escola no lugar, os próprios pais eram responsáveis pela educação dos filhos. Assim, aqueles que sabiam ler ou escrever alfabetizavam os mais novos nas próprias casas. O ensino básico regular não era ensinado. Com a decisão da comunidade de construir a escola, os moradores se reuniram e começaram sua construção, doando materiais e mão de obra. Para aqueles que moravam no povoado, essas grandes distâncias não eram um entrave para o estudo. Ao lado da escola, foi construída a cisterna. Essa cisterna servia para abastecer os potes de água da escola e também aos moradores já residentes naquele lugar.

A partir desse momento, com a construção da escola e da cisterna, começou a existir uma propulsão para a formação do povoado, as crianças que moravam lá embaixo, nas roças propriamente ditas, percorriam muitos quilômetros para estudar. Morar perto da escola e perto do poço, a partir de então, passou a ser visto como uma facilidade buscada para quem morava lá embaixo. A construção da escola pela comunidade e a educação como um dos fatores para formação do povoado mostram a auto-organização e a educação, levantada por Schumacher (1977) e Ávila (2006), como forma clara de produção do próprio bem-estar e permanência local. 
Também é relevante notar o significado da escola para a permanência das famílias no local. Quando se iniciam as migrações temporárias em 1976, muitos pais iam aos carvoeiros e às derrubadas das florestas com os filhos e mães, que ajudavam nos afazeres, seja cozinhando, lavando ou cuidando dos barracos nas florestas. Quando o povoado iniciou sua própria educação, a permanência se acentuou, pois destinavam-se aos carvoeiros somente os pais de famílias e os filhos mais velhos que já tinham "terminado o estudo". As mães ficavam no povoado para cuidar dos filhos mais novos que ainda estudavam.

No final da década de 1970 é construída a igreja da Comunidade, próxima ao lugar aonde foi construída a escola. Por meio de leilões e rifas, a igreja foi construída aos poucos com a ajuda da população. Antes da sua construção, as missas, casamentos e batizados eram realizados debaixo dos pés de pequi, ou de outra árvore qualquer.

De maneira resumida, pode-se afirmar que a década de 1970 foi marcada pelo início dessas alterações. As principais foram o início das migrações temporárias, a construção da escola comunitária, a cisterna de água e a construção da igreja que terminou na década seguinte.

Com essas alterações, a vida ainda permaneceu, acentuadamente, nas roças, ou "lá embaixo". As formas de morar e sobreviver ainda eram mantidas de forma tradicional. Na década seguinte, a vida cotidiana começou a se reconfigurar, e aquele modo de vida alterou-se com a vinda para o povoado. Três pontos são marcantes para compreender essas alterações a partir da chegada das políticas públicas que vão provocar a metabolização discutida por Ávila (2006). São elas: o loteamento, o encanamento e a chegada da energia, somadas a outras políticas de bem-estar.

\subsection{A subida: consolidação do povoado de Melancias}

Em 1983, o então prefeito de Brasília de Minas desapropriou o terreno em volta da escola, da cisterna e da igreja e loteou para a população que morava lá embaixo. As famílias começaram a comprar os terrenos e construir na área loteada. A formação da comunidade rural de Melancias inicia-se a partir desse momento. As primeiras casas construídas foram feitas de enchimento, como lá embaixo. Após algum tempo, começaram a ser construídas de alvenaria. Nesse período, alguns estabelecimentos comerciais começavam a aparecer. As primeiras "vendas", na linguagem do povoado, ficavam junto à residência do proprietário. Quem chegava para comprar alguma coisa ficava do lado de fora e, por vezes, "espiava" o interior das outras casas. O entrevistado A relata com risos essa expressão, "[...] era boteco, colocava uma tábua assim em cima do abobe [adobe], o cara, freguês não entrava dentro de casa não, ficava de fora né, era gurita, os homens era gurita (risos)".

As vendas representavam uma forma de organização local do espaço, além de pontos de socialização, pois muitos eram bares ou outras formas comerciais que buscavam suprir as necessidades de consumo da população. Elas passam a representar também a identidade do povoado em relação aos seus moradores. O vender fiado, muito comum, revela a confiança entre os moradores e a distinção do bom e do mal pagador entre os moradores da vizinhança.

Posteriormente, a cisterna foi substituída por um poço artesiano (1984). Com a construção do poço, o trabalho manual foi substituído pelas torneiras. Assim, os moradores colocavam os baldes debaixo da torneira, enchiam de água, colocavam na cabeça ou no carro de boi e levavam para suas residências. Como a água na região tem muito sal, constituindo-se em águas 
muito salobras, a água do poço continuou sendo muito usada até os dias atuais, mesmo com a construção dos encanamentos, já que, por meio dos poços, evitam-se águas salobras devido à profundidade da captação. Como no dizer dos moradores, por ser uma "água mais doce".

Em 1985, a escola comunitária, construída pela comunidade, foi derrubada e cedeu lugar a uma nova, feita de areia e cimento. Além disso, a escolaridade passa a ser até o ensino fundamental. Para terminar a educação básica, as crianças passaram a estudar na sede do município ou em outros povoados. A escola hoje tem 168 alunos matriculados, 5 salas de aula, 11 turmas, 16 docentes e 2 turnos de funcionamento (IDEB, 2015). Todavia carece de infraestruturas para complementar o aprendizado dos alunos, pois não conta com biblioteca, sala de leitura, laboratório de ciências, acesso à internet, auditório, parque infantil e outros fatores que prejudicam o desenvolvimento da própria comunidade, pois muitos alunos não têm condições de ter acesso a esses recursos fora da escola.

As transformações que estavam ocorrendo no povoado, produtoras de novos rearranjos comunitários, também produziram novas relações sociais. Com as sucessivas mudanças, novas formas associativas também surgiam. No mesmo ano de 1985, por exemplo, foi criada a associação do povoado. A formação da associação foi um marco importante na história do lugar, pois foi a primeira forma de organização local com fins políticos. Pensar a associação no contexto político ao longo da formação do povoado é muito importante para entender sua relevância. O entrevistado A é muito claro em definir a forma de participação política existente na região. "[...] Antes vinha um cara representante de um político lá e falava que era pra gente votar em fulano, a gente nem sabia quem era o fulano, não tinha televisão e não tinha rádio, era voto de cabresto que fala, né" (ENTREVISTADO A).

Com a formação da associação, foi criada a fábrica comunitária de farinha de mandioca, "a fabriqueta". Com ela, todas as famílias do povoado puderam fabricar suas próprias farinhas e vender o excedente. A partir desse momento, as políticas públicas que chegaram à comunidade foram intermediadas pela associação, como o Programa Um Milhão de Cisternas Rurais (P1MC) e a construção de outros poços artesianos.

Para que o desenvolvimento local ocorra, Ávila (2006) levanta a necessidade da incorporação das necessidades locais à agenda política de desenvolvimento regional e nacional, funcionando por meio da coprodução do bem público e respeitando as especificidades comunitárias. O conceito de incorporação aproxima-se do conceito de liberdade política de Sen (2000), pois é por meio da garantia de participação que a comunidade passa a escolher os rumos do seu desenvolvimento. Assim, um dos pilares para o desenvolvimento do povoado é o fortalecimento dos canais de participação e auto-organização da comunidade, para que, em conjunto com o Estado, consiga produzir bem-estar local.

Sen (2000) também afirma que as liberdades influenciam no funcionamento umas das outras. A associação comunitária passou a agir como agente do seu próprio desenvolvimento, rompendo em parte com as amarras clientelistas, devido a garantia das poucas políticas de segurança protetora que chegaram à época no povoado, como é o caso da água. A partir do momento em que o acesso à agua foi facilitado, assim como o acesso à educação, as relações de dependências abriram espaços para os direitos sociais.

A união das pessoas em comunidade, devido às intensas relações de parentesco, fator chave para a coesão gregária (ÁVILA, 2006), proporcionou a criação da casa comunitária da família, uma casa destinada à moradia daqueles que passavam por dificuldades e não tinham 
condições, por algum motivo, de morar em outra casa do povoado. O surgimento da casa, assim como da igreja, do rancho de palha e da fábrica comunitária, ocorreu por meio de doações de materiais e dinheiro, além da oferta da mão de obra pelos membros do povoado para sua construção.

Em 1986, a energia elétrica foi instalada na comunidade rural de Melancias. A partir desse momento, a formação mais intensa do povoado se inicia. Nas palavras do Entrevistado A, "[...] quando loteou, o pessoal já foi comprando e começando construir, e foi aumentando o povoado, quando colocou a luz e depois instalou a água, foi só encharcando o povoado". O acesso à energia não significou logo de imediato o acesso aos bens de consumo duráveis, a pobreza que se manifestava nas relações de trabalho nas florestas energéticas impedia o acesso a mercados devido aos baixos salários. Só a partir das políticas de distribuição de renda, na década de 2000, que a comunidade passou a acessar esses bens, como as motocicletas, muito comum no meio rural na atualidade. O entrevistado B relata que "[...] o povo veio comprar moto mesmo, foi mais na época que trabalhô em eucalipto na época que ficô bom, mas depois de dois mil pra cá o povo comprou moto demais aqui".

No ano de 1988, o posto de saúde foi construído. A população que tinha que se deslocar em grandes distâncias para realizar tratamentos e curativos simples, passou a ser atendida na própria comunidade. Contudo, nessa época, a atenção básica não tinha a assistência existente nos dias de hoje, fato que as benzedeiras e as curandeiras eram (e ainda que menos, mas até hoje são) protagonistas da saúde no povoado. Com a chegada do posto de saúde, diversos programas de atenção básica chegaram à comunidade, como o pré-natal, atenção odontológica, entre outros, havendo então uma mistura do conhecimento local com essa atenção básica. No entanto, mesmo com as mudanças de muitas pessoas para o povoado, o conhecimento de rezas, chás e orações continuaram muito presente no dia a dia daqueles que adoecem. Em 2006 foi construído um novo posto de saúde, mais amplo e mais confortável que o antigo.

Em 1988, junto com o posto de saúde, também foi inaugurado o posto telefônico. Isso representou a mudança do povoado para uma nova dinâmica. A vida lá embaixo, marcada pelo isolamento e ausente de dinâmicas modernas, se alterou completamente. As ligações telefônicas que eram feitas não representavam somente o contato das Melancias para outras regiões do País, geralmente eram destinadas a um parente ou um amigo distante que foi para São Paulo, ou para as grandes fazendas para a derrubada de eucalipto, corte de cana entre outros meios de trabalho em regime de migração pendular. Se, por um lado, o telefone permitiu o contato com parentes distantes, permitiu também o acesso à propostas de trabalho, muitas vezes enganosas em outras regiões, e que subordinavam a lógica da exploração e das condições desumanas de trabalho. Desse modo, a modernização chegou, mas carregou consigo subordinação e dependência. Em 1994, os orelhões foram instalados e o posto telefônico foi desativado.

Em 1988, com a chegada do encanamento, ocorreu uma melhoria nas condições de acesso à água. As pessoas não tinham que andar mais dois ou três quilômetros para buscar água na cabeça ou no jegue, agora tinham a água por meio da torneira na própria residência. Nesse momento, mudar para o povoado tinha duas vantagens, a água encanada que estava à disposição para o uso doméstico, rompendo com o esforço de buscá-la em grandes distâncias e a proximidade do poço artesiano, fonte de água doce para beber, lavar os cabelos e tomar banho.

Vale relatar que, mesmo com a facilidade da água por meio dos encanamentos, a dinâmica da busca pela água não acabou, mas se alterou. Quando a vida era lá embaixo, as pessoas 
responsáveis pela busca da água dentro do ambiente familiar eram as mulheres mais jovens e as crianças. Quando as famílias passaram a morar no povoado, a dinâmica de cooperação familiar se transformou, as ruas carregadas de laços de parentesco se formaram, representando a continuidade daquele modo de vida passado. No povoado, devido à facilidade de acesso à água no poço, principalmente pela proximidade, mesmo sendo as crianças e as mulheres mais jovens a continuarem a transportá-la, tornava-se possível o compartilhamento dessa água entre os vizinhos, principalmente quando não era possível que todas as famílias fossem buscá-la.

De maneira resumida, essas políticas foram as mais marcantes para a formação do povoado e garantiu a infraestrutura básica para a vida em comunidade na década de 1980. Após esse período, foram surgindo várias outras políticas públicas, como o asfalto, a construção da quadra poliesportiva, a praça e o calçamento. Enfim, políticas que são importantes para a manutenção da vida naquele lugar.

\subsection{A Organização socioespacial de Melancias: a influência da vida lá embaixo na organização territorial do povoado}

Com a mudança para o povoado, o território reordenado continuou carregando traços da dinâmica lá de baixo. Quando as famílias moravam nas roças, ou lá embaixo, o núcleo familiar era composto em média por 5 filhos, dividindo a tarefa doméstica entre buscar água e plantar, estabelecendo uma cooperação familiar muito intensa entre os membros das famílias. Com a subida, essa aproximação familiar se mantém com a mesma ajuda mútua entre os membros das famílias numerosas, fato que, quando o povoado se formou, as famílias mantiveram essa proximidade nos terrenos adquiridos como forma de manter o núcleo familiar próximo um ao outro, mantendo as mesmas características de quando se vivia lá embaixo. Em muitas ruas, a maioria dos domicílios vizinhos ou próximos uns aos outros são organizados por laços de parentesco.

O Povoado, então, se formou a partir de 49 núcleos familiares, que estabeleceram uma intensa relação de parentesco de $2^{\circ}$ e $3^{\circ}$ grau, influência notadamente das características do Norte de Minas antes da incorporação à SUDENE (Figura 1). Esses fatores familiares desencadeiam, até na atualidade, a solidariedade e a coesão gregária (ÁVILA, 2006) presentes no povoado. Esses dois conceitos manifestam-se nas construções realizadas pela comunidade e festas comunitárias tradicionais. Nas folias de reis e nas fogueiras de São João, festas tradicionais do povoado e da região, diversas famílias oferecem suas casas para as festas comunitárias, nas quais todas as pessoas da comunidade são convidadas para comer e beber à vontade por meio da solidariedade do festeiro. 

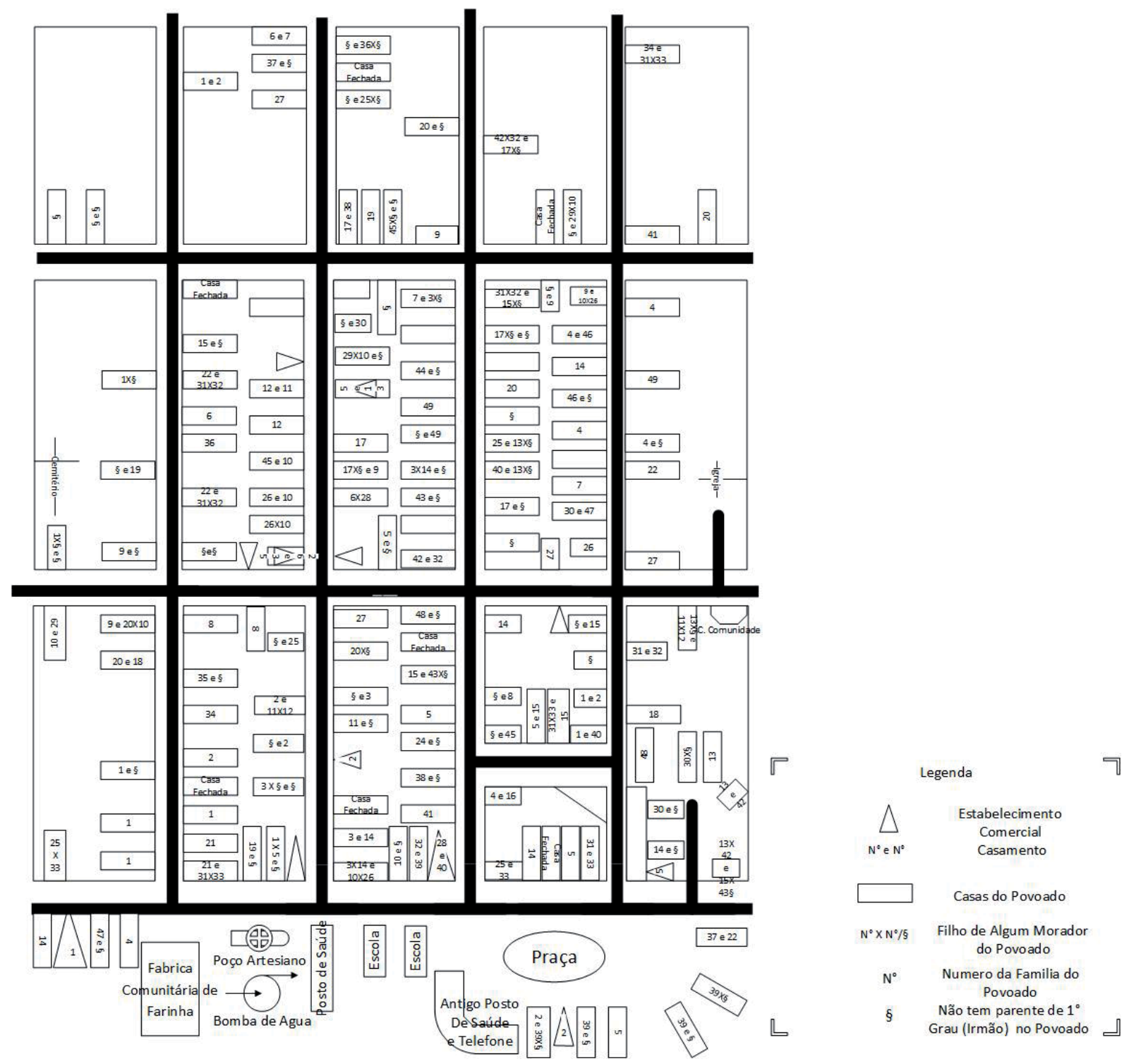

Figura 1 - Mapa parental da Comunidade Rural das Melancias pós transformações territoriais Fonte: Elaborado pelos autores.

Porém essa dinâmica nem sempre foi assim. Pode-se afirmar que essa dinâmica nas fogueiras comunitárias é nova em relação às antigas fogueiras. No passado, quando o cotidiano era marcado pela pobreza rural descrita no início desse capítulo, as fogueiras e as folias de reis eram marcadas por essa condição devido à pouca disponibilidade de comida e pela dificuldade manifestada nas relações de trabalho. O festeiro convidava poucos vizinhos para participar da festa oferecida.

A mudança no comportamento das festas ocorre por meio das políticas de combate à fome e distribuição de renda nos anos 2000. A erradicação da fome, fruto de políticas públicas, como Bolsa Família, PRONAF, P1MC, entre outras, possibilitou a segurança protetora da população local. Dessa forma, a ausência de fome permite a condição de agente de acordo com seus aspectos valorativos, permitindo ao indivíduo influenciar o meio no qual está inserido (SEN, 2000). Na comunidade, o aspecto da liberdade aparece e é refletido nas festas comunitárias.

As políticas que chegam na época de 2000 refletiram no aumento do desenvolvimento humano do Norte de Minas e da comunidade de Melancias. Dessa forma, pensar o desenvolvimento humano como forma de permanência apresenta uma evidente saída para o desenvolvimento local. 


\subsection{A possibilidade de pensar o local a partir da crítica ao desenvolvimento}

De maneira resumida, a história do Norte de Minas foi marcada pelos seguintes pontos: primeiro o Norte de Minas isolado, marcado pela autossuficiência e o surgimento dos cincos povos. Segundo, a integração da região à SUDENE, com Montes Claros e despontando como polo industrial da região, junto com a agricultura voltando-se para o agronegócio. E por último, as consequências dessas novas dinâmicas para a população local levando às migrações e ao cercamento. Quando marcado pelo isolamento, o Norte de Minas tinha sua produção voltada para as necessidades básicas da população, por vezes, abaixo das condições de subsistência, como nos períodos de seca prolongada. Essas formas tradicionais de produção levavam a um processo acumulativo de pobreza, presentes na fome, na falta de água e nas condições de moradia.

A inclusão da região à área de atuação da SUDENE, levou às inversões econômicas na região e à formação de capital. Duas marcantes alterações acontecem: a agricultura volta-se para o consumo industrial e, juntamente com a industrialização da cidade de Montes Claros e Pirapora, aumenta-se a produtividade da região.

A inserção dessas comunidades-localidades ao desenvolvimento regional leva o local a ser um elo na cadeia global de desenvolvimento (OLIVEIRA, 2001; FURTADO, 1984; ARRIGHI, 1998). As instalações de multinacionais na região, atraídas pelos incentivos fiscais da SUDENE e implantação das florestas energéticas que fornecem matéria-prima para a exportação de aço, construção civil e fábrica de celulose, se constituíram pela exploração da mão de obra presente nessas localidades. O local passa a fazer parte da semiperiferia e da periferia do desenvolvimento, participando ativamente do regime de trocas desiguais que caracteriza a diferença entre as regiões ricas e pobres (ARRIGHI, 1998). Com a nova posição do local nessa cadeia, novos papéis sociais surgiram nessas localidades.

Além da reorganização dos papéis sociais da comunidade, o êxodo levou a mão de obra para fora dessas localidades, impedindo que a formação e o emprego do capital local se desenvolvesse. Todavia o local apresentou respostas a essas dinâmicas. O DLEx e o DLEn existentes na organização comunitária no Povoado de Melancias (SEN, 2000; AVILA, 2006; SCHUMACHER, 1977) representaram a capacidade da comunidade em permanecer no território promovendo seu próprio desenvolvimento e o metabolizando a seu favor.

A migração das pessoas do povoado para os grandes centros não ocorreu de maneira definitiva, devido aos aspectos valorativos existentes no território, presentes no mapa parental da Figura 1 e nas lembranças do lugar evocadas sobre a vida em comunidade, como conta a entrevistada D,

[...] A única saudade que temos daquele tempo é da liberdade que nós tínhamos, de andar a cavalo, encontra os primos brincar, encontrava todo mundo na casa do meu avô, ia brincar e cantar, da liberdade nós temos muita saudade mas o resto era muito sofrido.

Desse modo, é possível fazer duas afirmações acerca do desenvolvimento local do Povoado. Primeiro, as políticas públicas presentes no DLEx permitiram a melhoria na vida local e a preservação dos aspectos valorativos da comunidade, como ocorreu durante a subida e a formação do povoado. Segundo, a auto-organização das pessoas, manifestada na construção da fábrica de farinha, na primeira escola do povoado, na casa comunitária da família, na formação da associação e nas fogueiras e folia de reis comunitárias, formaram os pilares centrais para a permanência. Pode-se entender como o espaço se constrói por meio da figura 1. A fábrica comunitária, a igre- 
ja, a escola e a casa comunitária correspondem ao DLEn; enquanto as outras políticas públicas representam o DLEx. As políticas públicas locais podem ser resumidas no quadro 2.

\begin{tabular}{|c|c|c|c|}
\hline Década de 1970 & Década de 1980 & Década de 1990 & Década de 2000/2010 \\
\hline $\begin{array}{l}\text { Cisterna } \\
\text { Igreja } \\
\text { Escola Comunitária } \\
\text { Primeiras Vendas }\end{array}$ & \multirow{2}{*}{$\begin{array}{l}\text { Loteamento } \\
\text { Aumento das Vendas } \\
\text { Reforma da Escola } \\
\text { Antigo Posto de Saúde } \\
\text { Posto de Telefone } \\
\text { Encanamento } \\
\text { Energia Elétrica } \\
\text { Poço Artesiano } \\
\text { Casa Comunitária da } \\
\text { Família }\end{array}$} & $\begin{array}{l}\text { Orelhões } \\
\text { Poucos Bens de } \\
\text { Consumo Duráveis } \\
\text { Bolsa Escola }\end{array}$ & $\begin{array}{l}\text { Bolsa Família e } \\
\text { Programas Sociais } \\
\text { Aumento dos Bens de } \\
\text { Consumo Duráveis } \\
\text { Praça }\end{array}$ \\
\hline \multirow[t]{2}{*}{$\begin{array}{l}\text { Vida no povoado: Vida } \\
\text { lá Embaixo e Poucas } \\
\text { Casas no Povoado }\end{array}$} & & \multirow[t]{2}{*}{$\begin{array}{l}\text { Vida no Povoado: } \\
\text { Consolidação do } \\
\text { Povoado e Migração }\end{array}$} & $\begin{array}{l}\text { Calçamento } \\
\text { Asfalto } \\
\text { Posto de Saúde } \\
\text { Quadra Poliesportiva }\end{array}$ \\
\hline & $\begin{array}{l}\text { Vida no Povoado: } \\
\text { Grande Êxodo para o } \\
\text { Povoado e Fora dele }\end{array}$ & & $\begin{array}{c}\text { Vida no Povoado: } \\
\text { Crescimento do Número } \\
\text { de Casas no Povoado } \\
\text { e Continuação da } \\
\text { Migração }\end{array}$ \\
\hline
\end{tabular}

Quadro 2 - Políticas Públicas no Povoado

Fonte: Elaborado pelos autores.

Todavia o desenvolvimento local do Povoado de Melancias é parte do desenvolvimento regional do Norte de Minas. O desabrochamento das capacidades locais de produção permitiu a inserção da comunidade nesse desenvolvimento, gerando renda e permanência. O conceito de formação, cultura e tecnologia intermediária (ÁVILA, 2006; FURTADO, 1984; SCHUMACHER, 1977), orientaram a formação do capital local de produção. As falas dos próprios entrevistados, quando perguntados sobre o que deveria ser feito para que Melancias se desenvolvesse, reforçam isso ao dizerem que "[...] primeiro lugar é gerar emprego depois você pode montar várias coisas" (ENTREVISTADO D). O entrevistado A salienta também que "[...] e hoje a pessoa vai pra cidade se ele não tiver uma profissão boa, se for pra viver de aluguel, ele não vive não". Com relação aos valores locais de permanência, ele é enfático, "[...] na roça o cara cria uma galinha não dá lucro, mas ele está vivendo um pouquinho né, tem um ovo pelo menos pra comer um frango, e na cidade tudo é comprado" (ENTREVISTADO A). Assim, os aspectos valorativos devem compor o desenvolvimento local como forma substantiva dessa comunidade.

\section{CONCLUSÃO}

De maneira geral, pode-se compreender a transformação da comunidade de Melancias por meio das transformações do Norte de Minas. Inicialmente, a existência de um Norte de Minas isolado, marcado pela autossuficiência entre a produção e o consumo, foram fatores chaves para desencadear a formação cultural sertaneja e o surgimento dos povos tradicionais locais. Em um segundo momento, o Norte de Minas é integrado à área mineira da SUDENE em 1963. Após a integração, o Norte de Minas passa a receber incentivos fiscais e acesso a créditos visando promover a formação de capital na região. A implantação de florestas energéticas e a modernização industrial podem ser considerados resultados das políticas implantadas na região nesse período. 
Ao mesmo tempo, o povoado de Melancias acompanhou essas transformações. O êxodo rural e a institucionalização das migrações temporárias após a seca de 1976 aconteceram concomitantemente com as políticas de modernização industrial e agrícolas implantadas na região. 0 povoado entrou na lógica desenvolvimentista moderna, pois, os moradores passam a ser obrigados a buscar empregos nas grandes monoculturas produtoras de carvão e eucalipto e participam, mesmo que involuntariamente, da operacionalização da cadeia produtiva agrícola instalada na região.

Assim, as migrações temporárias para o corte de eucalipto e fábricas de carvão absorveram a mão de obra da região por meio de salários baixos e que impediram a formação de capital local. O emprego da mão de obra não ocorreu na própria localidade, mas na formação do capital regional e, consequentemente, o desenvolvimento do Povoado passou a ser subordinado ao desenvolvimento da região. Todavia as ações da própria comunidade, articuladas com políticas de governo, orientaram o surgimento de poupança local, formação educacional e dinamizou novas bases produtivas, contribuindo para a permanência local. Além disso, a auto-organização comunitária, acompanhada de laços valorativos, constituíram-se como fundamentais para relações substantivas entre os moradores e na manutenção de seus laços familiares.

A constituição histórica do povoado de Melancias ocorreu entre o auto-organização comunitária e as políticas públicas implementadas no território. A fábrica comunitária de farinha, a primeira escola, a casa comunitária da família, a construção da igreja e as festas realizadas no povoado ocorreram por meio da coesão gregária e a solidariedade existente entre os moradores da comunidade. Por outro lado, sua constituição também aconteceu a partir da chegada da energia elétrica, loteamento, poço comunitário, encanamento entre outras políticas públicas que garantiram o bem-estar da comunidade. O resultado final disso pode ser visto na confluência interna e externa no desenvolvimento comunitário, no qual as casas dos moradores do Povoado se organizam sempre próximas aos próprios núcleos familiares.

Assim, o povoado de Melancias se mostra relevante na constituição da cadeia global de desenvolvimento. Ao mesmo tempo, ao buscar possibilidades de autonomia, considerando suas especificidades locais e suas capacidades internas, principalmente a partir de aspectos valorativos, tem proporcionado dinâmicas próprias de desenvolvimento. A formação do capital local e o desencadeamento dos meios de produção locais como alternativa às migrações temporárias se mostraram primordiais para que o desenvolvimento local ocorresse, mesmo que ainda de maneira tímida, em conjunto com o fortalecimento das políticas públicas destinadas à comunidade.

\section{REFERÊNCIAS}

ARRIGHI, G. A ilusão do desenvolvimento. 4. ed. Petrópolis: Vozes, 1998.

ÁVILA, V. F. Realimentando a discursão sobre teoria do desenvolvimento local. Interações, Campo Grande, v. 8, n. 13, p. 133-140, set 2006.

. Pressupostos para formação educacional e desenvolvimento local. Interações, Campo Grande, v.1, n. 1, p. 63-76, set. 2000.

COSTA, J. B. A. Cultura, natureza e populações tradicionais: o Norte de Minas como síntese da nação brasileira. Revista Verde Grande, Montes Claros, v. 1, n. 3, dez./fev. 2005.

CRESWELL, J. W. Projeto de pesquisa: métodos qualitativo, quantitativo e misto. 2. ed. Porto Alegre: Artmed, 2007.

CUNHA, M. G. C. Territorialidades sertanejas: permanência e transformações no espaço rural nortemineiro. São Paulo: Intermeios, 2012. 
Entre Cercas: permanências e transformações no espaço rural do sertão Norte Mineiro. In: ENCONTRO NACIONAL DE GEÓGRAFOS, 16., Porto Alegre, RS, 25-31 jul. 2010. Anais... Porto Alegre, 2010.

FONSECA, G. S. Migrações na mesorregião do Norte de Minas/MG: análise do censo demográfico de 2010. Belo Horizonte. 2015. Tese (Doutorado em Geografia - Tratamento da Informação Espacial) - Pontifícia Universidade Católica de Minas Gerais, Belo Horizonte, MG, 2015.

Espacialidades das migrações temporárias mirabelenses: implicações na territorialidade local. 2009. Dissertação (Mestrado em Geografia) - Pontifícia Universidade Católica de São Paulo (PUC), São Paulo, SP, 2009.

FRANÇA, I. S.; BARBOSA, R. S; SOARES, B. R. O sertão norte-mineiro e suas transformações recentes. Educare, Montes Claros, v. 2, p. 66-77, 2006.

FURTADO, C. Desenvolvimento e subdesenvolvimento. Rio de Janeiro: Contraponto, 2009.

. Em busca de novo modelo. São Paulo: Editora Paz e Terra, 2002.

Terra, 1984.

Reflexões sobre a cultura brasileira. In: Cultura e desenvolvimento em época de crise. Rio: Paz e . Mito do desenvolvimento econômico. 3. ed. São Paulo: Paz e Terra, 1974.

MOREIRA, H. F. Se for pra morrer de fome, eu prefiro morrer de tiro: o Norte de Minas e a formação de lideranças rurais. 2010. 129p. Dissertação (Mestrado de Ciências Sociais em Desenvolvimento, Agricultura e Sociedade) - Instituto de Ciências Humanas e Sociais, Universidade Federal Rural do Rio de Janeiro, Rio de Janeiro, RJ, 2010.

MYRDAL, G. Teoria econômica e regiões subdesenvolvidas. 3. ed. Rio de Janeiro: Saga, 1972.

NURKSE, R. Problemas de formación de capital en los países insuficientemente desarrolados. México: Fondo de Cultura Económica, 1953.

OLIVEIRA, F. Aproximações ao enigma: o que quer dizer desenvolvimento local. São Paulo: Instituto Polis, Programa Gestão Pública e Cidadania/EAESP/FGV, 2001.

PREBISCH, R. Dinâmica do desenvolvimento latino-americano. Rio de Janeiro: Fundo de Cultura, 1968.

RAMOS, G. A modernização em nova perspectiva: em busca do modelo da possibilidade. In: HEIDEMANN, F. G.; SALM, J. F (Org.). Políticas públicas e desenvolvimento: bases epistemológicas e modelos de análise. Brasília: UNB, 2009. p. 41-78.

ROCHA, M. E. M. Celso Furtado e a formação da cultura brasileira. Eptic (UFS), v. 14, n. 1, [s.p.], jan./abr. 2012. ROSTOW, W. W. Etapas do desenvolvimento econômico. 2. ed. Rio de Janeiro: Zahar, 1964.

SCHUMACHER, E. F. O negócio é ser pequeno: um estudo de economia que leva em conta as pessoas. Rio de janeiro: Zahar, 1977.

SEN, A. Desenvolvimento como liberdade. São Paulo: Companhia das Letras, 2000.

\section{Sobre os autores:}

Lucas Alves Prates: Graduado em Administração Pública pela Universidade Federal de Lavras e Pós-graduando em Política e Planejamento Urbano pelo Instituto de Pesquisa e Planejamento Urbano e Regional da Universidade Federal do Rio de Janeiro (IPPUR/UFRJ). E-mail: prateslucas10@gmail.com

José de Arimatéia Dias Valadão: Doutor em Administração pela Universidade Federal de Pernambuco (PROPAD/UFPE). Professor do Bacharelado em Administração Pública no Departamento de Administração e Economia (DAE/UFLA) e Coordenador do Programa de PósGraduação em Administração Pública (PPGAP/UFLA). E-mail: arimateiavaladao@hotmail.com 